\title{
Rapid growth and body size in infancy predict overweight/obesity at 2 years
}

\author{
C. ní Chaoimh ${ }^{1}$, D. M. Murray ${ }^{2,3}$, L. C. Kenny ${ }^{3}$, J. O. B. Hourihane ${ }^{2}$ and M. Kiely ${ }^{1,3}$ \\ ${ }^{1}$ Maternal and Infant Nutrition Research Group, ${ }^{2}$ Department of Paediatrics and Child Health and ${ }^{3}$ The Irish Centre \\ for Fetal and Neonatal Translational Research, Department of Obstetrics and Gynaecology, University College \\ Cork, Ireland
}

The global prevalence of obesity is increasing, even among children as young as preschool age ${ }^{(1)}$. Rapid infant growth and a larger body size in infancy have been implicated as risk factors for subsequent obesity in both childhood and adulthood ${ }^{(2)}$. The aim of this study was to determine the association between body size and rapid growth in the first 12 months of life and overweight or obesity at 2 years of age.

We defined weight status at 2 years using the UK-WHO $0-4$ year age-and-gender specific BMI charts ${ }^{(3)}$ in 1346 children who participated in the Cork BASELINE Birth Cohort Study.

Weight was measured at birth, 2, 6, and 12 months and age-and-gender specific standard deviation scores (SDSs) were generated using the UK-WHO growth reference data ${ }^{(3)}$. We identifiedinfants who displayed rapid growth, defined as an increase $>0.67$ in weight $\operatorname{SDS}^{(4)}$, between $0-2,0-6,2-6,6-12$, or $0-12$ months. Children with a BMI $>91^{\text {st }}$ percentile at 2 years were defined as overweight/ obese. Separate multivariate logistic regression models were developed to identify independent predictors of overweight/obesity at 2 years. Candidate predictors were: a weight SDS in the highest quartile at birth, 2, 6, or 12 months and rapid growth during each of the age intervals. All models were adjusted for birth weight SDS, parity, gestational age, maternal third level education status and smoking during pregnancy.

Overall, $58 \%$ of children displayed rapid growth during at least one age interval. There was a significantly higher $(P<0 \cdot 001)$ prevalence of overweight/obesity at 2 years among these children than their counterparts who did not display rapid growth during any age interval in the first 12 months $(29.7$ vs. $12.9 \%)$. Rapid growth over any individual age interval or having a weight SDS in the highest quartile at birth or at 2, 6, or 12 months was associated with an increased risk of overweight/obesity at 2 years (see table).

\begin{tabular}{|c|c|c|c|c|}
\hline & $\begin{array}{c}\text { Prevalence } \\
(\%)\end{array}$ & $\begin{array}{l}\text { Odds ratio } \\
\text { (OR) }\end{array}$ & $95 \% \mathrm{CI}$ & $P$-value \\
\hline \multicolumn{5}{|c|}{ Rapid growth $(\uparrow>0.67$ inweight SDS) } \\
\hline $0-2$ months & $10 \cdot 2$ & $2 \cdot 92$ & $1 \cdot 92,4 \cdot 44$ & $<0 \cdot 001$ \\
\hline $2-6$ months & $29 \cdot 7$ & $2 \cdot 71$ & $1.99,3.68$ & $<0.001$ \\
\hline $0-6$ months & $25 \cdot 7$ & $4 \cdot 58$ & $3 \cdot 29,6 \cdot 39$ & $<0 \cdot 001$ \\
\hline $0-12$ months & $35 \cdot 7$ & 1.93 & $1 \cdot 35,2 \cdot 75$ & $<0 \cdot 001$ \\
\hline 6-12 months & $16 \cdot 0$ & $5 \cdot 02$ & $3 \cdot 52,7 \cdot 18$ & $<0 \cdot 001$ \\
\hline $\begin{array}{l}\text { Any age interval in } \\
0-12 \text { months }\end{array}$ & $58 \cdot 0$ & $4 \cdot 38$ & $3 \cdot 09,3 \cdot 21$ & $<0 \cdot 001$ \\
\hline \multicolumn{5}{|c|}{ Weight SDS in the highest quartile } \\
\hline Birth & - & 1.99 & $1 \cdot 47,2 \cdot 67$ & $<0 \cdot 001$ \\
\hline 2 months & - & $3 \cdot 20$ & $2 \cdot 30,4 \cdot 45$ & $<0.001$ \\
\hline 6 months & - & $5 \cdot 52$ & $4 \cdot 05,7 \cdot 53$ & $<0 \cdot 001$ \\
\hline 12 months & - & $7 \cdot 90$ & $5 \cdot 76,10 \cdot 83$ & $<0.001$ \\
\hline
\end{tabular}

We have found that a rapid increase in weight SDS or a body weight at the higher end of the distribution during infancy is associated with a greater risk of overweight/obesity in early childhood. The risk associated with having a weight SDS in the highest quartile increased with age, suggesting that intervention should begin as early as possible in infancy. Rapid growth between $0-2$, 0-6 and 6-12 months was associated with a greater risk of overweight/obesity than rapid growth between $0-12$ months suggesting that growth should be monitored at regular intervals during infancy to identify those at risk. Infancy may be a critical period for the development of obesity and identifying modifiable determinants of rapid weight gain during this period may be critical for the prevention of subsequent obesity.

This work was supported by the National Children's Research Centre.

1. de Onis M Blossner M, Borghi E. (2010). Am J Clin Nutr 92(5), 1257-64.

2. Baird J, Fisher D, Lucas P, et al. (2005). BMJ 331(7522), 929.

3. The UK_WHO Growth Charts: Early Years. London: RCPCH, 2009.

4. Ong KK, Loos RJ. (2006). Acta Paediatr 95(8), 904-8. 